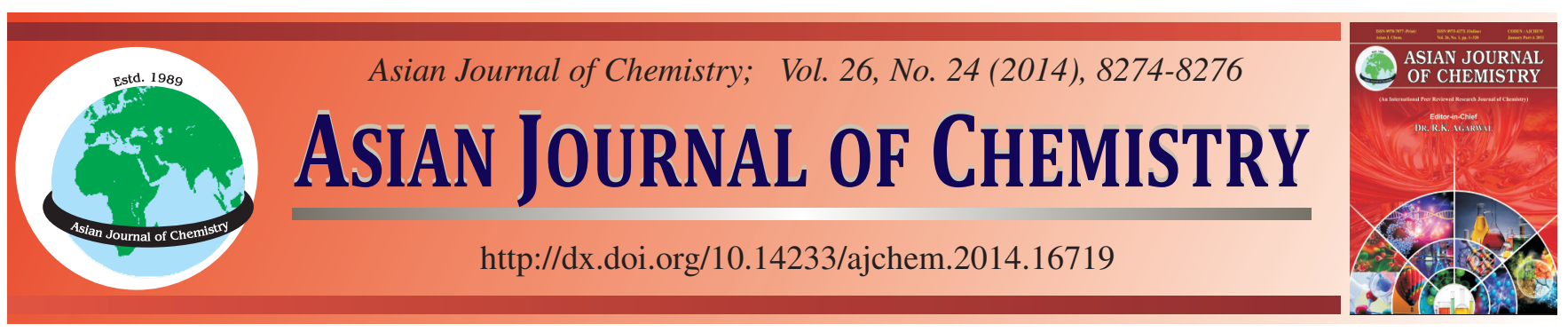

\title{
Crystal Structure and Conformational Analysis of Iridoid Glycoside Methylcatalpol
}

\author{
Lei Chen ${ }^{1}$, BinXiao Su ${ }^{2}$, Jingwen Wang ${ }^{1}$ and Aidong Wen ${ }^{1, *}$
}

${ }^{1}$ Department of Pharmacy, Xijing Hospital Fourth Military Medical University, Xi'an 710032, Shaanxi Province, P.R. China

${ }^{2}$ Department of Anesthesiology, Xijing Hospital Fourth Military Medical University, Xi'an 710032, Shaanxi Province, P.R. China

*Corresponding author: E-mail: chennwu@126.com

Received: 19 November 2013;

Accepted: 24 February 2014;

Published online: 1 December 2014;

AJC-16344

The crystal structure of methylcatalpol $\left(\mathrm{C}_{16} \mathrm{H}_{24} \mathrm{O}_{10}, \mathrm{Mr}=376.35\right)$ has been determined by single crystal X-ray diffraction analysis. The compound crystallizes in the monoclinic crystal system with space group $\mathrm{P} 2_{1}$ and unit cell parameters: $\mathrm{a}=7.5598(15), \mathrm{b}=9.6705(19), \mathrm{c}$ $=12.103(2) \AA$ and $\mathrm{Z}=2$. Both cyclopentane ring and pyran ring of the compound adopt envelope conformation and Glc moiety exists in chair conformation. The chirality of the asymmetric carbon atoms follows: C1(S), C5(R), C6(S), C7(S), C8(S), C9(S), C21(S), C22(R), C23(S), C24(S) and C25(R). Moreover, a complex network of hydrogen bonds occurred between neighboring molecules.

Keywords: Iridoid glycoside, Methylcatapol, Crystal structure.

\section{INTRODUCTION}

$\mathrm{X}$-ray diffraction analysis has been increasingly used to determine the molecular structure, conformation and absolute configuration of natural organic compounds ${ }^{1}$. Up to now, few papers on crystal structures of iridoid glycoside have been published $^{2}$. Iridoid glycoside is cyclopentanoid monoterpene derivative and exists broadly in plants of many families ${ }^{3}$. Because of the structural characteristics of unstable, iridoid glycoside is difficult to crystallize.

The methylcatalpol, \{1a,1b,2,5a,6,6a-hexahydro-1a(hydroxyl-methyl)-6-methoxy oxireno [4,5]cyclopenta [1,2c]pyran-2-yl- $\beta$-D-glucopyranoside $\}$, which extracted from the leaves of Buddlejadavidii, is a compound belonging to the family of iridoid glycoside. It is a mono-O-methyl derivative of catalpol (Fig. 1).

The methylcatalpol's NMR spectroscopy was studied in the literature ${ }^{4}$. In this paper, we report the molecular and crystal structure of methylcatalpol by single crystal X-ray diffraction study and the conformational analysis of the title molecule. The accurate determination of the structure of methylcatalpol will be useful for understanding its function and property.

\section{EXPERIMENTAL}

The methylcatalpol was isolated and purified as literature procedure $^{5}$. Colourless and transparent crystals suitable for $\mathrm{X}$-ray analysis were obtained on crystallizing the product using methanol. IR (KBr, $\left.v_{\max }, \mathrm{cm}^{-1}\right)$ : 3372, 3221, 2901, 1653, 1626,
1415, 1377, 758. ESIMS: $m / z$ 399.2 [M + Na $]^{+}$. Anal. Calcd for $\mathrm{C}_{16} \mathrm{H}_{24} \mathrm{O}_{10}$ : C, 51.06; H, $6.38 \%$. Found: C, 51.10; $\mathrm{H}, 6.41 \%$.

X-ray crystallography: Single crystal X-ray diffraction data were collected on a BRUKER SMART APEX CCD diffractometer with $\mathrm{MoK}_{\alpha}$ radiation $(\mathrm{k}=0.71073 \AA)$ in the range of $1.73<\theta<25.09$ at $296 \mathrm{~K}$. The data integration and reduction were processed with SAINT software. The structures were solved by the direct method using SHELXTL and embarked on a full-matrix least-squares refinement on $\mathrm{F}^{2}$ with SHELXL97 program $^{6}$. All non-hydrogen atoms were refined anisotropically. All hydrogen atoms were determined via difference Fouriermaps and refined with isotropic atomic displacement parameters.

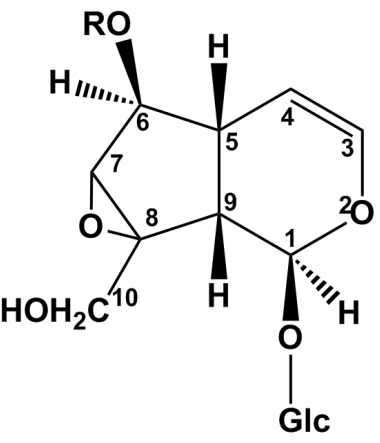

Catalpol: $\mathbf{R}=\mathbf{H}$

Methylcatapol: $\mathrm{R}=\mathrm{CH}_{3}$

Fig. 1. Chemical structures of catalpol and methylcatalpol 


\section{RESULTS AND DISCUSSION}

The methylcatalpol crystallizes in a $\mathrm{P} 2_{1}$ space group in the monoclinic system (Table-1). The molecular skeleton of methylcatalpol (Fig. 2) is notably similar to that of aucubin ${ }^{7}$. The difference is that methylcatalpol has a methoxyl group attached to C-6 and exhibits an epoxide ring between C-7 and $\mathrm{C}-8$ in the molecule, compared to aucubin. The bond lengths and bond angles were found to be consistent approximately with the reported values for similar bonds of aucubin: $\mathrm{C}-\mathrm{C}$ lengths range from $1.302(5) \AA[\mathrm{C}(4)-\mathrm{C}(3)]$ to $1.566(5) \AA[\mathrm{C}(9)-$ $\mathrm{C}(5)]$ and C-O lengths range from 1.398(4) $\AA[\mathrm{C}(1)-\mathrm{O}(1)]$ to $1.450(4) \AA[\mathrm{C}(7)-\mathrm{O}(4)]$ while angles range from $59.7(2)^{\circ}$ $[\mathrm{O}(4)-\mathrm{C}(7)-\mathrm{C}(8)]$ to $124.1(4)^{\circ}[\mathrm{C}(4)-\mathrm{C}(3)-\mathrm{O}(2)]$. Both cyclopentane ring (C5-C6-C7-C8-C9) and pyran ring (C1-O2C3-C4-C5-C9) of the parent glucoside adopt envelope conformation. The Cremer-Pople puckering parameters obtained using the program PLATON for each ring are as follows ${ }^{8}$ : For cyclopentane ring, $\mathrm{Q}=0.292(4) \AA, \Phi=184.9(8)^{\circ}$ and for pyran ring, $Q=0.431(4) \AA, \Theta=52.0(5)^{\circ}, \Phi=79.9(6)^{\circ}$. The dihedral angle between cyclopentane and pyran rings is $132.24^{\circ}$. There are four chiral carbon atoms $(\mathrm{C} 1, \mathrm{C} 5, \mathrm{C} 6, \mathrm{C} 7, \mathrm{C} 8$ and $\mathrm{C} 9)$ in the parent glycoside. Identification of chiral centers and their $(\mathrm{R} / \mathrm{S})$-configuration show that the chirality of the asymmetric carbon atoms follows: (S), (R), (S), (S), (S) and (S). The Glc

\begin{tabular}{cc}
\multicolumn{3}{c}{ TABLE-1 } \\
CRYSTAL DATA AND STRUCTURE REFINEMENT DETAILS \\
\hline Empirical formula & $\mathrm{C}_{16} \mathrm{H}_{24} \mathrm{O}_{10}$ \\
Chemical formula weight $\left(\mathrm{M}_{\mathrm{r}}\right)$ & 376.35 \\
Temperature $(\mathrm{K})$ & $296(2)$ \\
Wavelength $(\AA)$ & 0.71073 \\
Crystal system & Monoclinic \\
Space group & $\mathrm{P} 2_{1}$ \\
$\mathrm{a}(\AA)$ & $7.5598(15)$ \\
$\mathrm{b}(\AA)$ & $9.6705(19)$ \\
$\mathrm{c}(\AA)$ & $12.103(2)$ \\
$\alpha\left({ }^{\circ}\right)$ & $90.000(3)$ \\
$\beta\left({ }^{\circ}\right)$ & $103.896(3)$ \\
$\gamma\left({ }^{\circ}\right)$ & $90.000(3)$ \\
$\mathrm{V}\left(\mathrm{A}^{3}\right)$ & $858.9(3)$ \\
$\mathrm{Z}$ & 2 \\
$\mathrm{D}_{\text {calc }}\left(\mathrm{Mg} / \mathrm{m}^{3}\right)$ & 1.455 \\
$\mathrm{~F}(000)$ & 0.122 \\
Absorption coefficient $\left(\mathrm{mm}^{-1}\right)$ & 400 \\
$\theta$ Range for data collection & $1.73-25.09$ \\
Reflections collected / unique & $4354 / 2617$ \\
Data / restraints / parameters & $2617 / 1 / 251$ \\
Goodness-of-fit on $\mathrm{F}^{2}$ & 0.872 \\
Final R indices $[\mathrm{I}>2 \sigma(\mathrm{I})]$ & $\mathrm{R}_{1}=0.0393$, \\
& $w \mathrm{R}_{2}=0.0885$ \\
Largest diff. peak and hole $\left(\mathrm{e} \AA^{-3}\right)$ & 0.190 and -0.168 \\
\hline
\end{tabular}

moiety was found to adopt chair conformation with ringpuckering parameters $\mathrm{Q}=0.569(4) \AA, \Theta=5.9(3)^{\circ}, \Phi=$ $347(4)^{\circ}$. In addition, the chirality of the five chiral atoms (C21 to $\mathrm{C} 25)$ are $(\mathrm{S}),(\mathrm{R}),(\mathrm{S}),(\mathrm{S})$ and $(\mathrm{R})$, respectively.

Within the asymmetric unit, there are three intramolecular hydrogen bonds (Table-2). The hydrogen bonds $\mathrm{O}(5)-\mathrm{H}(5) \ldots \mathrm{O}(6)$ and $\mathrm{O}(7)-\mathrm{H}(7) \ldots \mathrm{O}(6)$ form two five-membered rings, respectively. Another six-member hydrogen-bonded ring is also formed through the $\mathrm{N}(1)-\mathrm{H}(1) \ldots \mathrm{O}(2)$ hydrogen bond, with atoms $\mathrm{C} 3$, $\mathrm{C} 8$ and $\mathrm{C} 9$. These intramolecular hydrogen bonds help to stabilize the molecule. The water molecule is serving as a hydrogen bonding hub by a bifurcated donor hydrogen bond to two hydroxyl groups, as represented by $\mathrm{O}(10)-\mathrm{H}(10 \mathrm{~A}) \ldots \mathrm{O}(1)$ and $\mathrm{O}(10)-\mathrm{H}(10 \mathrm{~B}) \ldots \mathrm{O}(10)$ and by a bifurcated acceptor hydrogen bond from two other hydroxyl groups as represented by $\mathrm{O}(5)-$ $\mathrm{H}(5) \ldots \mathrm{O}(10)$ and $\mathrm{O}(6)-\mathrm{H}(6 \mathrm{C}) \ldots \mathrm{O}(10)$. These intermolecular interactions are manifested to result in the formation of chains of molecules and further the adjacent chains interact as shown in the lattice structure.

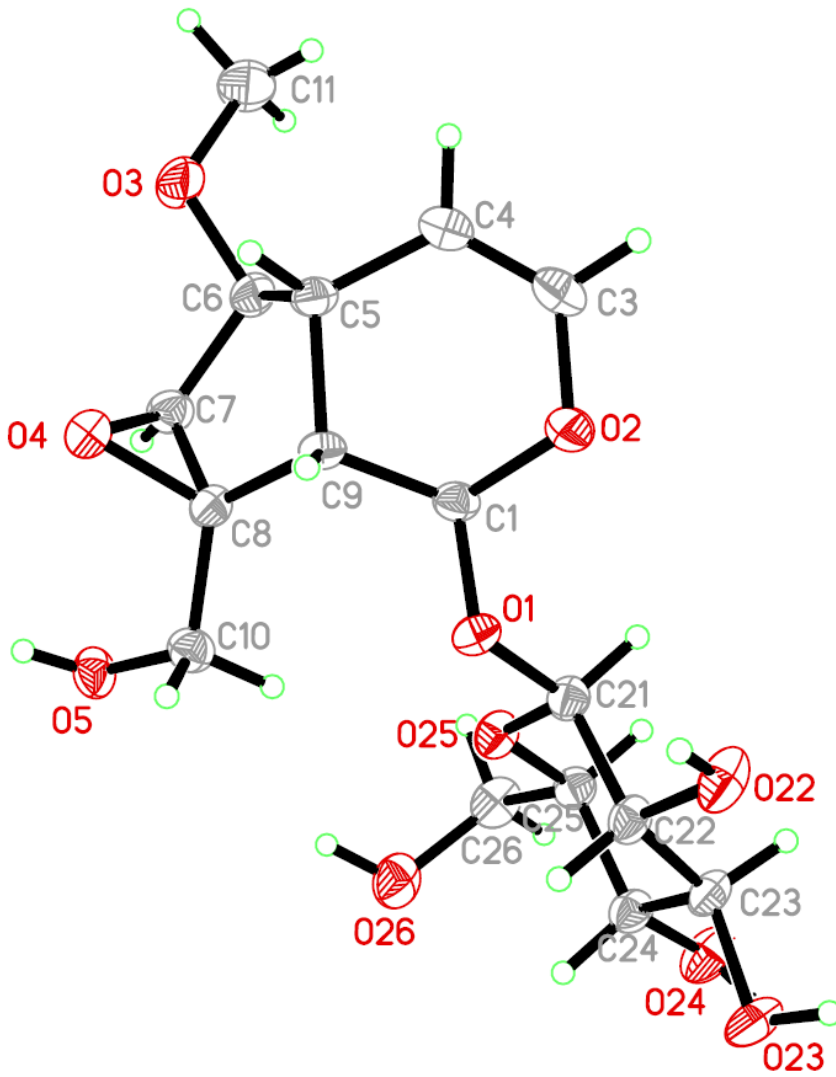

Fig. 2. ORTEP drawing of methylcatalpol, the all thermal ellipsoids are drawn at $30 \%$ probability level

TABLE-2

HYDROGEN BONDS DATA FOR METHYLCATALPOL

\begin{tabular}{|c|c|c|c|c|}
\hline D-H...A & $\mathrm{d}(\mathrm{D}-\mathrm{H})[\AA]$ & $\mathrm{d}(\mathrm{H} . . \mathrm{A})[\AA]$ & $\mathrm{d}(\mathrm{D} . . \mathrm{A})[\AA]$ & $\angle \mathrm{DHA}\left[{ }^{\circ}\right]$ \\
\hline $\mathrm{O}(5)-\mathrm{H}(5 \mathrm{~A}) \ldots \mathrm{O}(3)^{\# 1}$ & 0.82 & 1.97 & $2.768(3)$ & 165.0 \\
\hline $\mathrm{O}(22)-\mathrm{H}(22) \ldots \mathrm{O}(5)^{\# 2}$ & 0.82 & 1.90 & $2.668(3)$ & 156.0 \\
\hline $\mathrm{O}(24)-\mathrm{H}(24) \ldots \mathrm{O}(22)^{\# 3}$ & $0.93(7)$ & $2.66(7)$ & $3.387(4)$ & $136(6)$ \\
\hline $\mathrm{O}(26)-\mathrm{H}(26) \ldots \mathrm{O}(22)^{\# 4}$ & $0.90(5)$ & $1.96(5)$ & $2.766(4)$ & $147(5)$ \\
\hline $\mathrm{O}(23)-\mathrm{H}(23) \ldots \mathrm{O}(26)^{\# 2}$ & $0.91(5)$ & $1.86(5)$ & $2.752(4)$ & $163(4)$ \\
\hline
\end{tabular}

Symmetry transformations used to generate equivalent atoms: ${ }^{\# 1}:-\mathrm{x}+2, \mathrm{y}+1 / 2,-\mathrm{z}+2 ;^{\# 2}: \mathrm{x}-1, \mathrm{y}, \mathrm{z} ;{ }^{\# 3}:-\mathrm{x}, \mathrm{y}+1 / 2,-\mathrm{z}+1 ;{ }^{\# 4}: \mathrm{x}+1, \mathrm{y}, \mathrm{z}$ 
An extensive network of methylcatalpol is formed by hydrogen bonding interactions based on five hydroxyl groups of the glycoside (Fig. 3). Three hydroxyl groups participate at the same time in the formation of two hydrogen bonds, the $\mathrm{O}(5)-\mathrm{H}(5 \mathrm{~A}) \ldots \mathrm{O}(3), \mathrm{O}(22)-\mathrm{H}(22) \ldots \mathrm{O}(5)$ and $\mathrm{O}(26)-\mathrm{H}(26) \ldots \mathrm{O}(22)$. That is, $\mathrm{OH}$ plays a role both as a donor of a hydrogen bond and as an acceptor of another hydrogen bond. Two hydroxyl groups are the only donor, the $\mathrm{O}(24)-\mathrm{H}(24) \ldots \mathrm{O}(22)$ and $\mathrm{O}(23)-$ $\mathrm{H}(23) \ldots \mathrm{O}(26)$ (Table-2). These intermolecular interactions are manifested to result in the formation of molecular chains and further the adjacent chains interact as shown in the lattice structure.

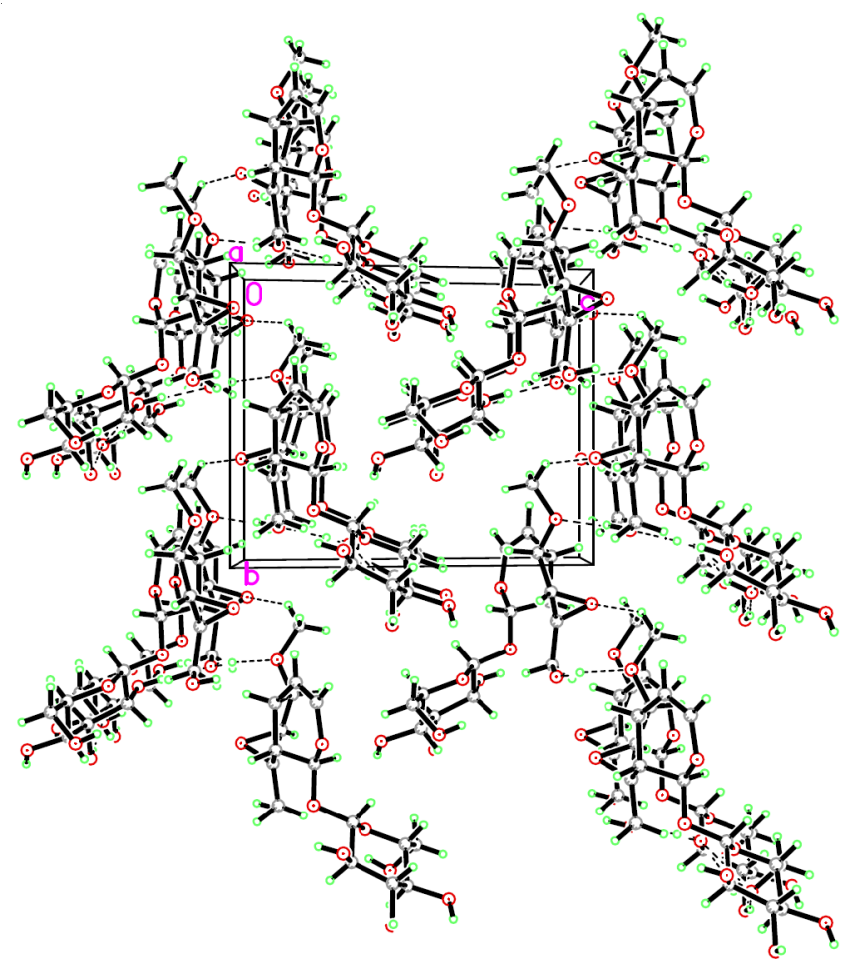

Fig. 3. Molecular packing of methylcatalpol, viewed along the a-axes. The dashed lines represent hydrogen bonds

\section{Conclusion}

In this study, the crystal structure of methylcatalpol has been determined by single crystal X-ray diffraction analysis. The results demonstrated for the first time that methlycatalpol crystallizes in the monoclinic crystal system with space group $\mathrm{P} 2_{1}$. Both cyclopentane ring and pyran ring of the compound adopt envelope conformation and Glc moiety exists in chair conformation. A complex network of hydrogen bonds occurred between neighboring molecules.

Supplementary data: Crystallographic data (excluding structure factors) for the structure reported in this paper have been deposited with the Cambridge Crystallographic Data Centre as Supplementary Publication No. CCDC 852812. Copies of the data can be obtained free of charge on application to the CCDC, 12 Union Road, Cambridge, CB2 1EZ, UK (www: http://www.ccdc.cam.ac.uk).

\section{ACKNOWLEDGEMENTS}

This study was financially supported by National Natural Science Foundation of China (No. 81100901).

\section{REFERENCES}

1. Y. Li, Y. Zhao, G.P. Yang, M.J. Wang, Y.M. Zhang and W.J. Sun, J. Chem. Crystallogr., 41, 163 (2011).

2. M.X. Li, Z.P. Jia, R.X. Zhang, Z.D. Hu and X. Tian, Carbohydr. Res., 343, 561 (2008).

3. J. Suomi, H. Sirén, K. Hartonen and M.-L. Riekkola, J. Chromatogr. A, 868, 73 (2000).

4. R.M. Perez Gutierrez, R.F. Rangel and E.G. Baez, Chem. Nat. Comp., 44, 35 (2008).

5. R.M.P. Gutierrez, R.V. Solis, E.G. Baez and F.M. Martinez, Phytother. Res., 20, 542 (2006).

6. G.M. Sheldrick, SHELXTL Version 5.10. Bruker AXS Inc., Madison, Wisconsin, USA, (1997).

7. Y. Li, Y. Zhao, Y.M. Zhang, M.J. Wang and W.J. Sun, Carbohydr. Res., 344, 2270 (2009).

8. A.L. Spek, PLATON, A Multipurpose Crystallographic Tool. Utrecht University, Utrecht, The Netherlands (2008). 